Prepared for the U.S. Department of Energy

under Contract DE-AC05-76RL01830

\title{
Mobile Ice Nucleus Spectrometer
}

\author{
GR Kulkarni \\ GL Kok
}

May 2012

Pacific Northwest

NATIONAL LABORATORY

Proudly Operated by Battelle Since 1965 



\title{
DISCLAIMER
}

This report was prepared as an account of work sponsored by an agency of the United States Government. Neither the United States Government nor any agency thereof, nor Battelle Memorial Institute, nor any of their employees, makes any warranty, express or implied, or assumes any legal liability or responsibility for the accuracy, completeness, or usefulness of any information, apparatus, product, or process disclosed, or represents that its use would not infringe privately owned rights. Reference herein to any specific commercial product, process, or service by trade name, trademark, manufacturer, or otherwise does not necessarily constitute or imply its endorsement, recommendation, or favoring by the United States Government or any agency thereof, or Battelle Memorial Institute. The views and opinions of authors expressed herein do not necessarily state or reflect those of the United States Government or any agency thereof.

\author{
PACIFIC NORTHWEST NATIONAL LABORATORY \\ operated by \\ BATTELLE \\ for the \\ UNITED STATES DEPARTMENT OF ENERGY \\ under Contract DE-AC05-76RL01830
}

Printed in the United States of America
Available to DOE and DOE contractors from the Office of Scientific and Technical Information,
P.O. Box 62, Oak Ridge, TN 37831-0062;
ph: (865) 576-8401
fax: $(865)$ 576-5728
email: reports@adonis.osti.gov

\begin{abstract}
Available to the public from the National Technical Information Service, U.S. Department of Commerce, 5285 Port Royal Rd., Springfield, VA 22161 ph: (800) 553-6847 fax: $(703) 605-6900$ email: orders@ntis.fedworld.gov online ordering: http://www.ntis.gov/ordering.htm
\end{abstract}

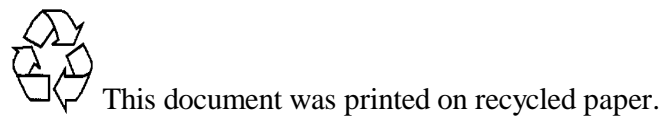


PNNL-21384

\title{
Mobile Ice Nucleus Spectrometer
}

\author{
GR Kulkarni
}

GL Kok

May 2012

Prepared for the U.S. Department of Energy

under Contract DE-AC05-76RL01830

Pacific Northwest National Laboratory

Richland, Washington 99352 


\section{$\underline{\text { Report for: }}$}

Project Title: Mobile Ice Nucleus Spectrometer

Company Name: Droplet Measurement Technologies

Principal Investigator: Gregory L. Kok

Date: April 26, 2012

From: Dr. Gourihar Kulkarni, Pacific Northwest National Laboratory, Richland, WA USA

\section{Summary:}

This first year report presents results from a computational fluid dynamics (CFD) study to assess the flow and temperature profiles within the mobile ice nucleus spectrometer. 


\section{Contents:}

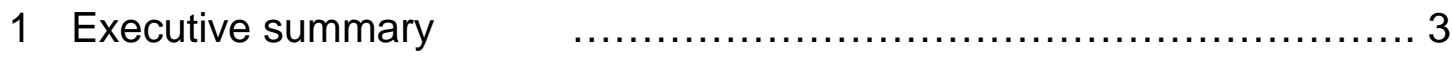

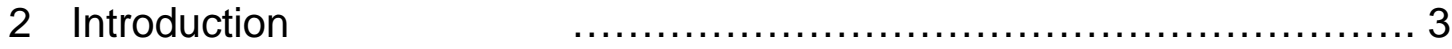

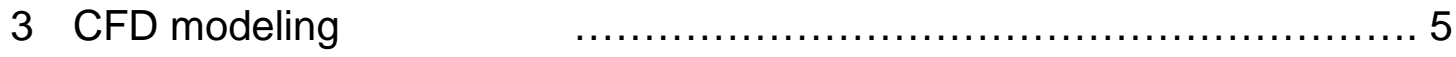

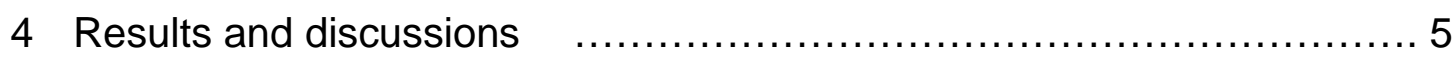

4.1 CFD modeling of the ice chamber exit system $\ldots \ldots \ldots \ldots \ldots \ldots \ldots 5$

4.2 CFD modeling of the ice chamber plates $\quad \ldots \ldots \ldots \ldots \ldots \ldots \ldots .7$

4.3 Calculation of the aerosol lamina $\quad \ldots \ldots \ldots \ldots \ldots \ldots \ldots 12$

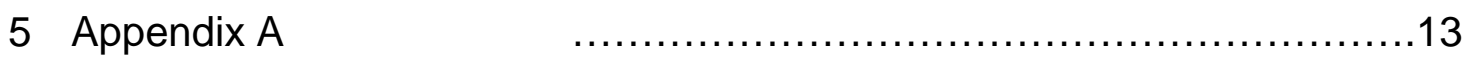




\section{Executive summary:}

Computational fluid dynamics (CFD) simulations were undertaken to assess the velocity streamlines and temperature profiles within the mobile ice nucleus spectrometer (MINS). The CFD modeling was done at the Pacific Northwest National Laboratory (PNNL) using the commercial CFD software FLUENT (Ver. 6.3, ANSYS). The work meets the specifications provided by Droplet Measurement Technologies (DMT) with reference to commercialization of MINS system. Following specific features were discerned from the CFD simulations.

$\checkmark$ Exit geometry of the MINS is sensitive to the particle size.

$\checkmark$ Particles at the center line of the MINS remain undisturbed by the particles.

$\checkmark$ Modification to the MINS exit geometry can lead to improvement in operation of the MINS, particularly automation of icing. However, the new designs are susceptible to the droplet shattering.

$\checkmark$ Temperature gradient within the two plates of the MINS can influence the environmental conditions such as temperature and supersaturation.

$\checkmark$ CFD results were also used to verify the location of the aerosol lamina within the MINS.

The main results corresponding to above findings are discussed briefly.

\section{Introduction:}

DMT proposed to develop a rugged, fast response, continuous flow, MINS. The MINS will have the accuracy and reliability required by the research community to detect ice nuclei for application in laboratory, field, and aircraft operations. For the development DMT collaborated with the research institute (Pacific Northwest National Laboratory - PNNL) as a requirement for the Department of Energy's (DOE) Small Business Technology Transfer (STTR) program. Fig. 1 provides a photograph of the MINS. 

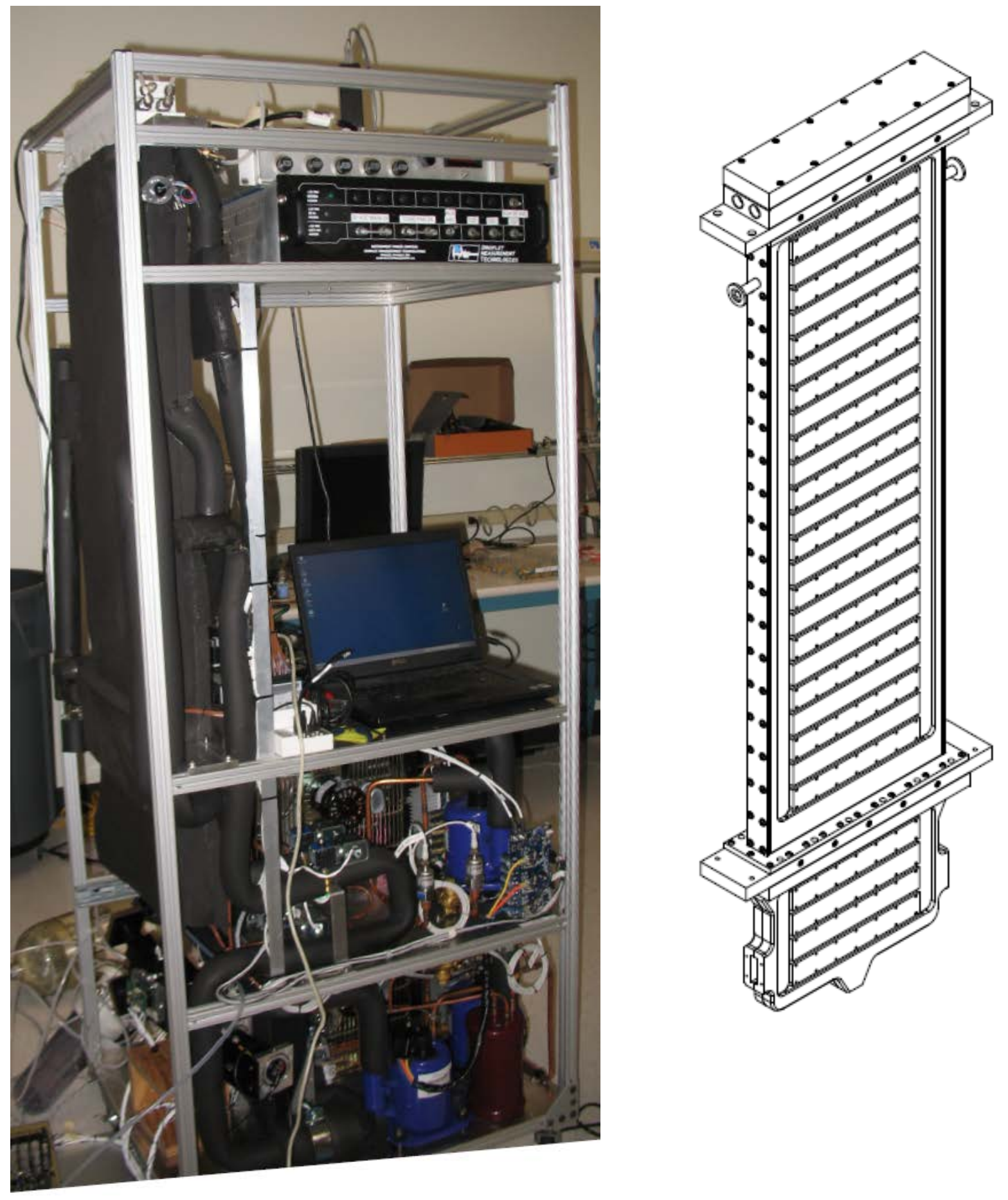

Figure 1: Photograph of the MINS (left). Details of ice chamber plates without insulation shown in the right panel.

Briefly, MINS systems consist of vertical ice chamber plates (insulated, shown on the left), a control software system and the refrigeration system (bottom two shelves within the rack). The ice chamber plates (without insulation) are shown in Fig. 1 (right panel). 
CFD tasks were identified to take the developments in phase II and produce a commercial ice nucleus counter or MINS. These are listed below.

1. CFD modeling of the ice chamber exit system to understand the aerosol particle behavior that includes losses and impaction.

2. CFD modeling of the ice chamber plates to understand the wall effects on the temperature and supersaturation calculations.

3. CFD validated numerical calculations to predict the aerosol lamina within the ice chamber when two plates of the ice chamber are maintained at the different temperature and a prescribed flow is developed.

Key results from each task are presented.

\section{CFD modeling:}

The CFD modeling was done at the Pacific Northwest National Laboratory (PNNL) using the commercial CFD software FLUENT (Ver. 6.3, ANSYS) to address above tasks. FLUENT solves conservation equations for mass, energy, and momentum to calculate flow properties (e.g., velocity profiles for various flow configurations). Three-dimensional simulations were utilized for this work.

The FLUENT pre-processor software GAMBIT (Ver. 6.3, ANSYS) was used to build the physical, or "mesh," the MINS domain. Approximately 1 million cells with variable mesh density were used. Relatively higher mesh density was used for the areas with rapid changes of dependent variables (e.g., velocity, temperature) to make use of computing power most efficiently.

The FLUENT "discrete phase model" was used to understand how particle trajectory was influenced by the PCVI flow characteristics. This model calculates the trajectories of individual particles in the gas phase. The effects of turbulence were included by enabling a stochastic tracking (random walk) model which includes the effects of instantaneous turbulent velocity fluctuations. Injected particles were modeled as spheres with density equal to ice particle.

\section{Results and Discussions:}

\subsection{Task 1: CFD modeling of the ice chamber exit system:}

Fig. 2 shows the droplet trajectories passing through the exit geometry of the ice chamber. It was observed that particles upto 30 micrometers follow the streamlines and do not impact the exit 
system. Fig. $2 \mathrm{f}$ shows the particles with 50 micrometer in diameter will impact the exit system of the ice chamber. A better way to take the particles out of the system needs to be designed.

a)

\begin{tabular}{l}
$2.79 \mathrm{e}+00$ \\
$2.65 \mathrm{e}+00$ \\
$2.51 \mathrm{e}+00$ \\
$2.37 \mathrm{e}+00$ \\
$2.23 \mathrm{e}+00$ \\
$2.09 \mathrm{e}+00$ \\
$1.95 \mathrm{e}+00$ \\
$1.82 \mathrm{e}+00$ \\
$1.68 \mathrm{e}+00$ \\
$1.54 \mathrm{e}+00$ \\
$1.40 \mathrm{e}+00$ \\
$1.26 \mathrm{e}+00$ \\
$1.12 \mathrm{e}+00$ \\
$9.77 \mathrm{e}-01$ \\
$8.38 \mathrm{e}-01$ \\
$6.98 \mathrm{e}-01$ \\
$5.59 \mathrm{e}-01$ \\
$4.19 \mathrm{e}-01$ \\
$2.79 \mathrm{e}-01$ \\
$1.40 \mathrm{e}-01$ \\
$0.00 \mathrm{e}+00$ \\
\hline
\end{tabular}

c)

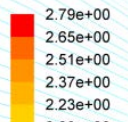
$2.23 \mathrm{e}+00$ $2.09 \mathrm{e}+00$ $1.95 \mathrm{e}+00$ $1.82 \mathrm{e}+00$
$1.68 \mathrm{e}+00$ $1.54 \mathrm{e}+00$ $1.40 \mathrm{e}+00$

$1.26 \mathrm{e}+00$

$1.12 \mathrm{e}+00$
$9.77 \mathrm{e}-01$

9.77e-01

$8.38 \mathrm{e}-01$

$6.98 \mathrm{e}-0$

4. $19 \mathrm{e}-01$

$2.79 \mathrm{e}-01$

$1.40 \mathrm{e}-01$

$0.00 \mathrm{e}+00$

e)

$2.79 \mathrm{e}+00$
$2.65 \mathrm{e}+00$
$2.51 \mathrm{e}+00$
$2.37 \mathrm{e}+00$
$2.23 \mathrm{e}+00$
$2.09 \mathrm{e}+00$
$1.95 \mathrm{e}+00$
$1.82 \mathrm{e}+00$
$1.68 \mathrm{e}+00$
$1.54 \mathrm{e}+00$
$1.40 \mathrm{e}+00$
$1.26 \mathrm{e}+00$
$1.12 \mathrm{e}+00$
$9.77 \mathrm{e}-01$
$8.38 \mathrm{e}-01$
$6.98 \mathrm{e}-01$
$5.59 \mathrm{e}-01$
$4.19 \mathrm{e}-01$
$2.79 \mathrm{e}-01$
$1.40 \mathrm{e}-01$
$0.00 \mathrm{e}+00$

b)

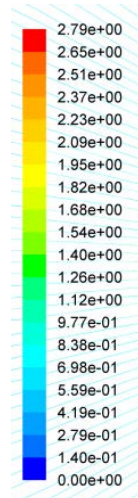

d)

$2.79 \mathrm{e}+00$
$2.65 \mathrm{e}+00$
$2.51 \mathrm{e}+00$
$2.37 \mathrm{e}+00$
$2.23 \mathrm{e}+00$
$2.09 \mathrm{e}+00$
$1.95 \mathrm{e}+00$
$1.82 \mathrm{e}+00$
$1.68 \mathrm{e}+00$
$1.54 \mathrm{e}+00$
$1.40 \mathrm{e}+00$
$1.26 \mathrm{e}+00$
$1.12 \mathrm{e}+00$
$9.77 \mathrm{e}-01$
$8.38 \mathrm{e}-01$
$6.98 \mathrm{e}-01$
$5.59 \mathrm{e}-01$
$4.19 \mathrm{e}-01$
$2.79 \mathrm{e}-01$
$1.40 \mathrm{e}-01$
$0.00 \mathrm{e}+00$

f)

Figure 2: Various size particle trajectories passing the exit system of the ice chamber. Panels a) to $f$ ) are the flow trajectories of 1, 3, 5, 7, 30, and 50 particle size micrometers, respectively. Flow is from left to right. Grey line shows the geometry of the exit geometry. 
The effect of the exit geometry on the flow streamlines within the ice chamber was investigated. As per the ice chamber theory, the sheath flow acts as the carrier gas flow for the aerosol particles within the ice chamber. It is possible that turbulence at the exit geometry may affect the location of the aerosols. Fig. 3 shows the aerosol streamlines and sheath flow streamlines.

It was observed that aerosol particles released at the inlet of ice chamber remained at central lamina till the exit geometry, indicating no influence of turbulence on the particles. Also the it was observed that the sheath flow is well mixed, but does not alter the location of the aerosol lamina.

a)

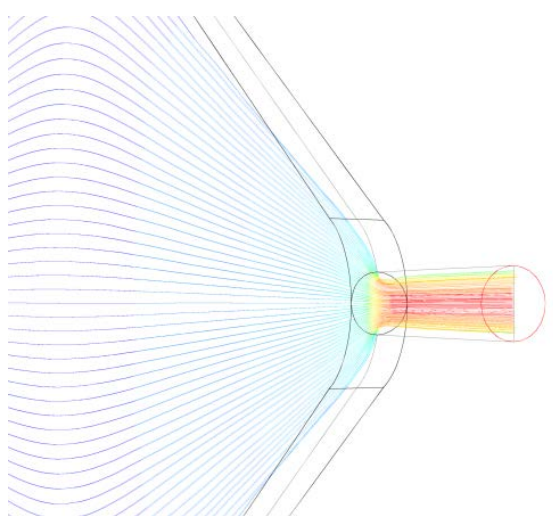

b)

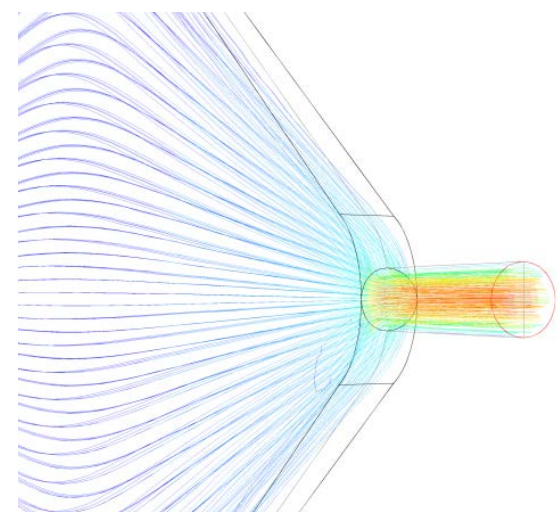

Figure 3: a) Particle trajectories of 10 micrometer particles, and b) gas flow streamlines of sheath flow.

\subsection{Task 2: CFD modeling of the ice chamber plates:}

The temperature gradient across the ice chamber wall can influence the temperature and supersaturation calculations. Sensitivity simulations were performed to understand the effect of temperature gradient on the aerosol temperature within the chamber.

Fig. 4 shows the various sections of the ice chamber and respective temperature values that are used for the simulations. Temperature was defined within the horizontal grooves, where refrigeration coils are inserted. The temperature values used to define the top, middle, and bottom sections were $253 \mathrm{~K}, 248 \mathrm{~K}$, and $243 \mathrm{~K}$, respectively.

Fig. 5 shows the temperature distribution across the plate with time. Approximately after 120 seconds steady state is achieved. 


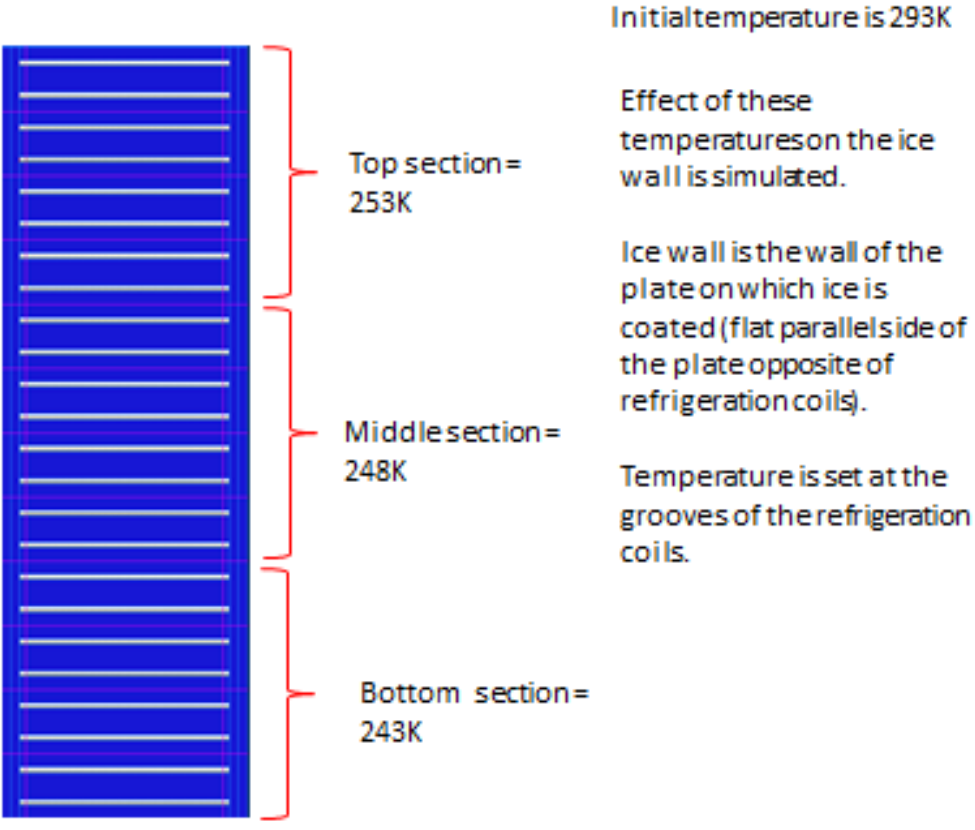

Figure 4: Ice chamber plate showing different sections that are maintained at different temperature to understand the how the gradient across plate result in the overall temperature gradient. 
a)

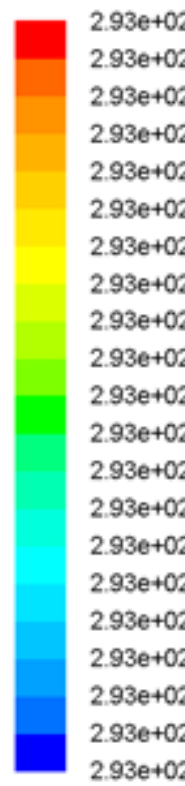

b)

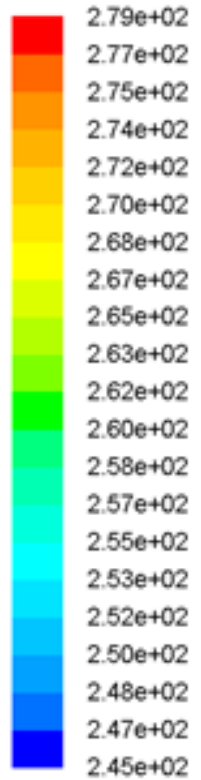

Temperature distribution on the icewall

Time $=0$ seconds

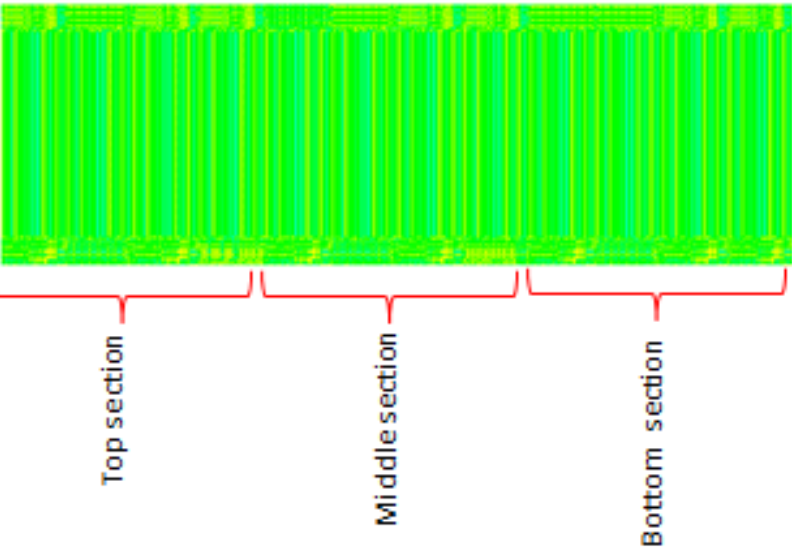

Temperature distribution on the icewall

Time $=2$ seconds

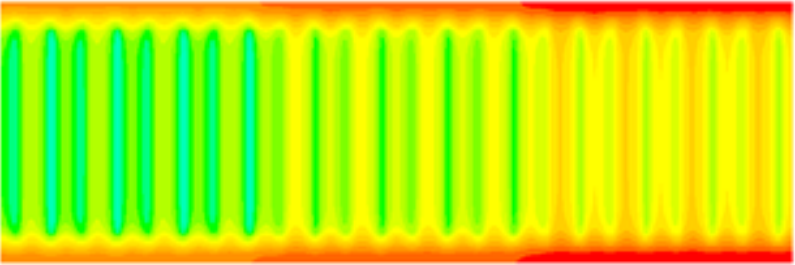


c)

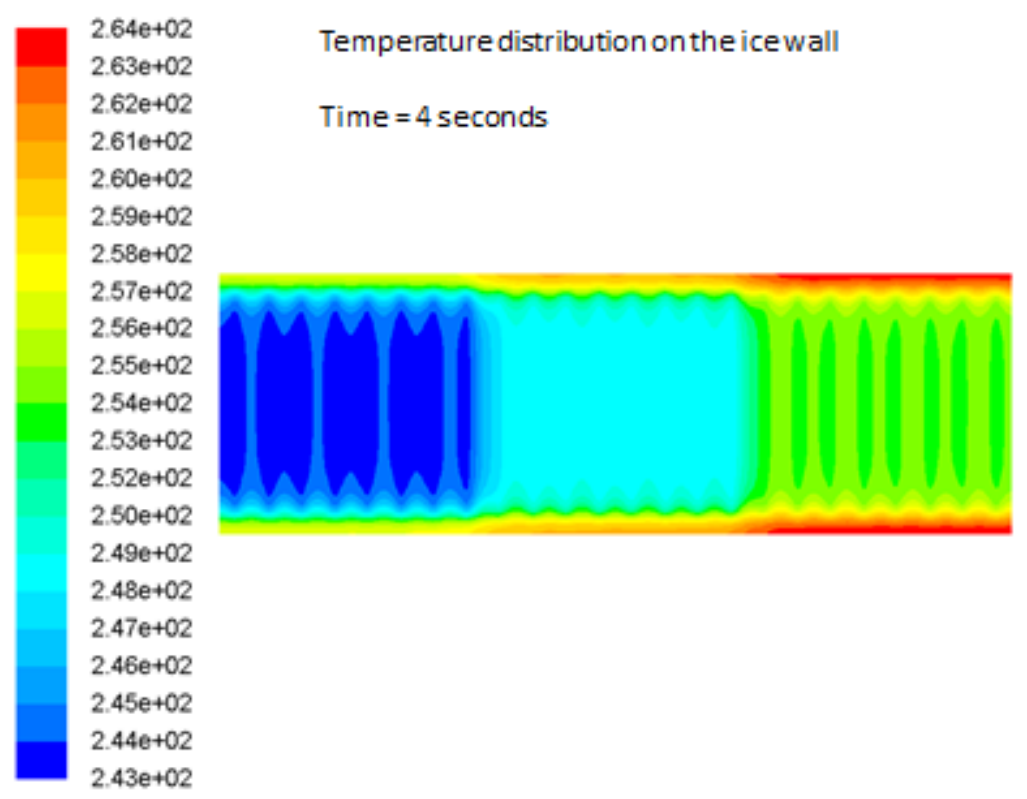

$\begin{array}{ll}2.56 \mathrm{e}+02 & \text { Temperature distribution on the ice wall } \\ 2.55 \mathrm{e}+02 & \\ 2.55 \mathrm{e}+02 & \\ 2.54 \mathrm{e}+02 & \\ 2.53 \mathrm{e}+02 & \\ 2.53 \mathrm{e}+02 & \\ 2.52 \mathrm{e}+02 & \\ 2.51 \mathrm{e}+02 & \\ 2.51 \mathrm{e}+02 \\ 2.50 \mathrm{e}+02 \\ 2.49 \mathrm{e}+02 \\ 2.49 \mathrm{e}+02 \\ 2.48 \mathrm{e}+02 \\ 2.48 \mathrm{e}+02 \\ 2.47 \mathrm{e}+02 \\ 2.46 \mathrm{e}+02 \\ 2.46 \mathrm{e}+02 \\ 2.45 \mathrm{e}+02 \\ 2.44 \mathrm{e}+02 \\ 2.44 \mathrm{e}+02 \\ 2.43 \mathrm{e}+02\end{array}$ 
e)

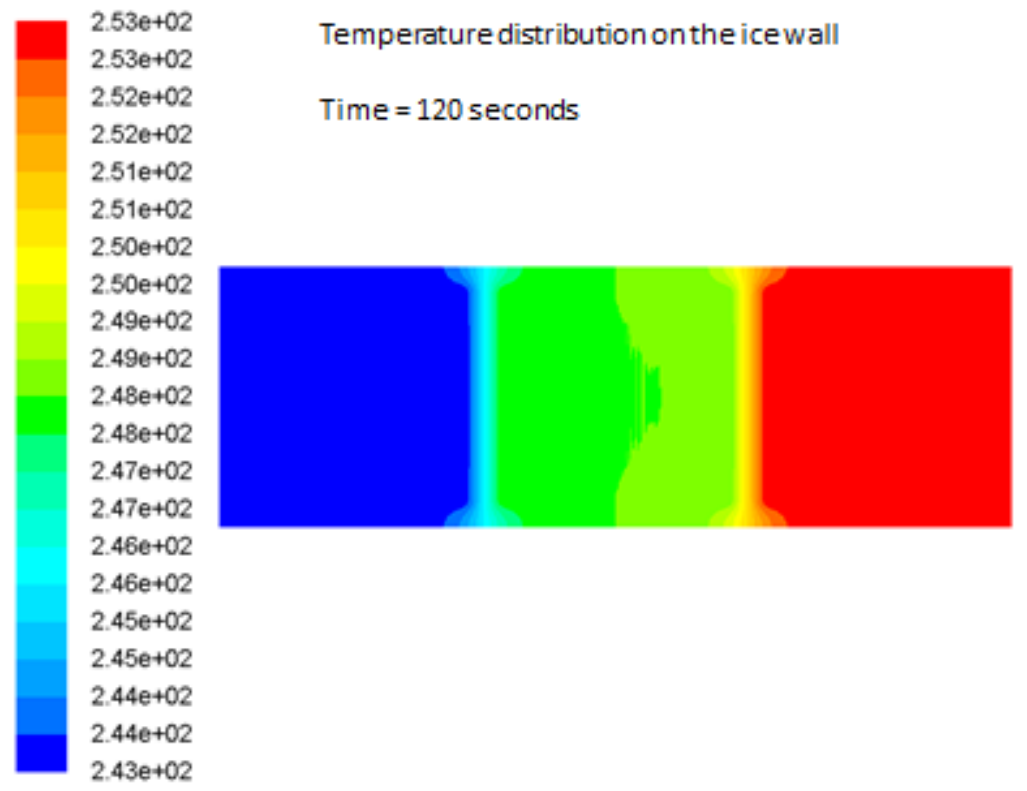

Figure 5: Panels a) to e) shows the temperature gradient across the plate as a function of time.

The effect of temperature gradient on the aerosol temperature, the particles which are positioned at the central of the chamber are shown in figure 6. It can be concluded that temperature gradient across the plate has a profound effect on the aerosol temperature profile. Temperature gradient across the plate should be minimized. 


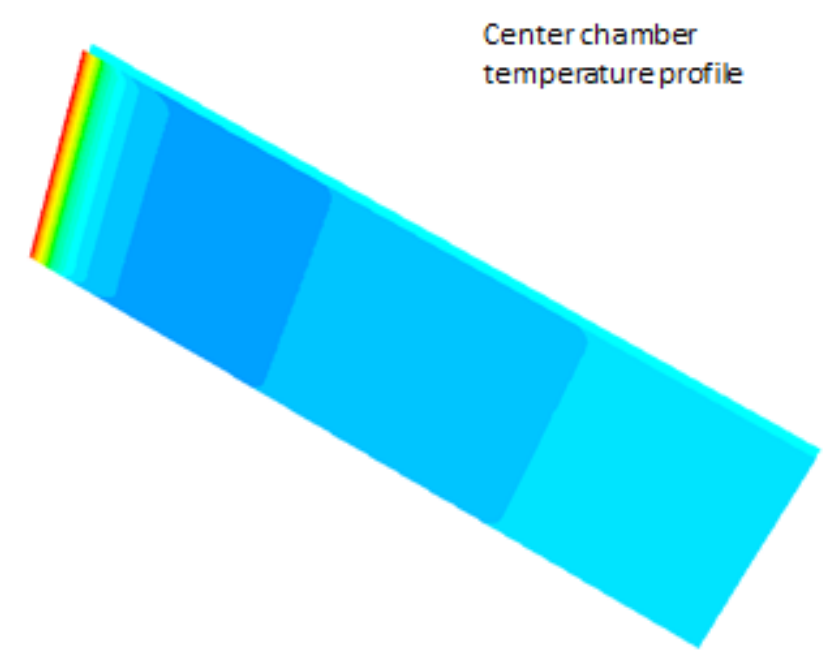

Figure 6: Temperature profile of the aerosol located at the central axis of the ice chamber.

\subsection{Task 3: Calculation of the aerosol lamina:}

The supersaturation profile within the chamber is calculated based on the temperature gradient across the two plates. Due to thermophoresis effect the aerosol lamina is shifted towards the colder region and this affect the temperature and supersaturation calculations. Therefore depending upon the flow conditions, corrections to these calculations should be applied. The formulae for these calculations based on the previous study are calculated and presented in the appendix A. These calculations are also verified using CFD simulations (simulations results not shown here). 


\section{$5 \quad$ Appendix A}

This section is carried forward titled as follows:

“Calculation of aerosol lamina coordinates and corresponding supersaturation values within the parallel plate vertical ice chamber:" 


\section{Calculation of aerosol lamina coordinates and corresponding supersaturation values within the parallel plate vertical ice chamber:}

\section{1) Calculating the coordinates of aerosol lamina:}

\section{Inputs used:}

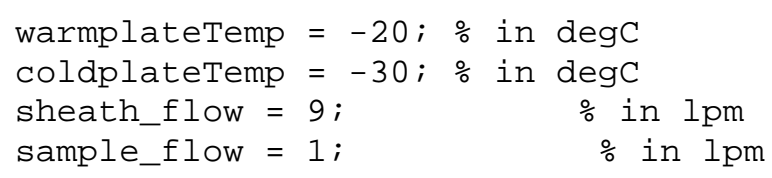

\section{Constants used:}

$\mathrm{d}=5 \mathrm{e}-03$; \% half distance between the plates is $5 \mathrm{~mm}$, in $\mathrm{m}$

Temp_avg $=($ warmplateTemp + coldplateTemp $) / 2+273 ; \%$ average temperature in $\mathrm{K}$

rhoair $=\left(101.325^{*} 1 \mathrm{e} 03\right) /\left(287.058^{*} \mathrm{Temp} \_\right.$avg $) ; \%$ assuming sea level pressure, in $\mathrm{kg} / \mathrm{m} 3$

deltaT $=($ warmplateTemp+273) $-($ coldplateTemp+273 $) ; \%$ temperature difference between the plates, in $\mathrm{K}$

$\mathrm{mu}=\left(1.458 \mathrm{e}-06^{*} \mathrm{Temp} \_a v g \wedge(3 / 2)\right) /($ Temp_avg+110.4)\% Sutherland dynamic

viscosity of air, in Ns/m2

crossarea $=2{ }^{*}{ }^{*} 0.3 ;$ \%cross sectional area of the chamber, in $\mathrm{m} 2$

flow $=$ sheath_flow + sample_flow; \% total flow, in lpm

$\mathrm{Q}=$ flow $^{*}(0.001 / 60) ; \%$ volumetric flow rate, in $\mathrm{m} 3 / \mathrm{sec}$

Vmean $=\mathrm{Q} /$ crossarea; $\%$ mean velocity, in $\mathrm{m} / \mathrm{sec}$

$\mathrm{g}=9.81 ; \%$ in $\mathrm{m} / \mathrm{s} 2$

$U=1 /$ Temp_avg; \% volume coefficient expansion of air assuming ideal gas behavior, in per $\mathrm{K}$

$A=(3 / 2)^{*}$ Vmean; $\%$ it is also called the centerline velocity (not used here, but original paper Sinnerwalla and Alofs 1973 have used this definition)

$B=\left(\right.$ rhoair $\left.{ }^{*}{ }^{\star} g^{\star} d^{\wedge} 2^{*} \operatorname{deltaT}\right) /\left(12^{*} \mathrm{mu}\right)$;

The velocity profile was calculated by solving the following equation (Rogers, 1988),

$$
V(Z, \Delta T)=\frac{3}{2} \bar{V}\left(1-\frac{Z^{2}}{d^{2}}\right)+\frac{\rho_{a} U g d^{2} \Delta T}{12 \mu}\left[\left(\frac{Z}{d}\right)^{3}-\left(\frac{Z}{d}\right)\right]
$$

substituting for $\mathrm{A}$ and $\mathrm{B}$, we get,

$$
V(Z, \Delta T)=A\left(1-\frac{Z^{2}}{d^{2}}\right)+B\left[\left(\frac{Z}{d}\right)^{3}-\left(\frac{Z}{d}\right)\right]
$$


Where $V$ is the velocity, $\bar{V}$ is the mean velocity, $\mathrm{Z}$ is the distance from the centerline of the flow, and $2 \mathrm{~d}$ is the plate separation distance $(=10 \mathrm{~mm})$. Other constants are defined above. Total volumetric flow rate (or mass flux), $\mathrm{Q}=\int_{-d}^{d} V(Z, \Delta T)=2 \mathrm{~d} . \bar{V}$, where $\mathrm{d}=0$ at midway between the plates.

For our work, we divide the $\mathrm{Q}$ profile as per the mass flux distribution.

To find the lamina coordinates, a and b (see below, Fig.1 from Rogers, 1988) we integrate in the two limits: $-\mathrm{d}$ to $\mathrm{a}$ and $\mathrm{b}$ to $\mathrm{d}$.
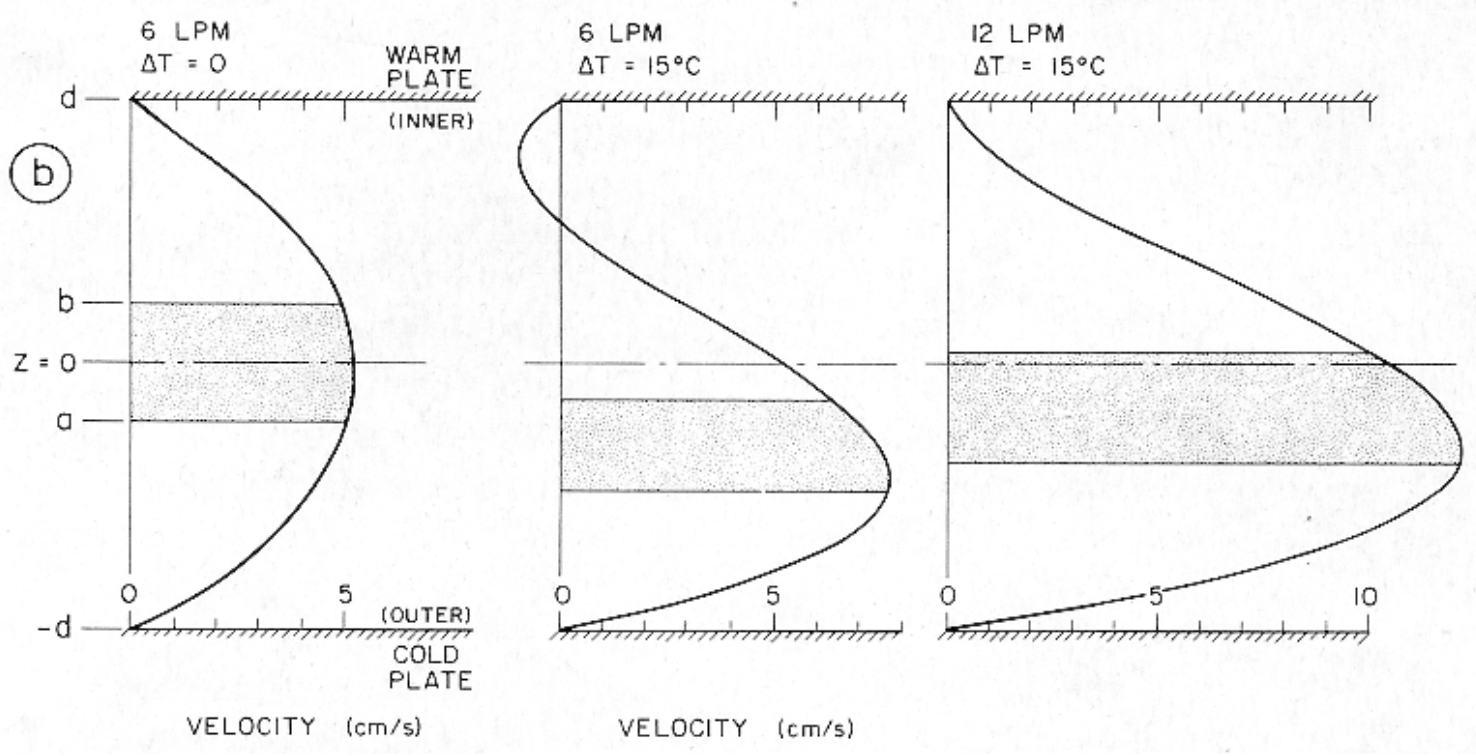

But for simplicity we will integrate from $\mathrm{b}$ to $\mathrm{d}$, Qint $=\int_{b}^{d} V(Z, \Delta T)$, and find the lamina coordinate ' $\mathrm{b}$ ' where: $50 \%$ of mass flux is on either side of the co-ordinate and co-ordinates where $45 \%$ and $55 \%$ of mass flux from warm plate is distributed.

Integrating Qint in the limits from $b$ to d, yields,

Qint $=A\left[d-\frac{d}{3}-b+\frac{b^{3}}{3 d^{2}}\right]+B\left[\frac{d}{4}-\frac{d}{2}-\frac{b^{4}}{4 d^{3}}+\frac{b^{2}}{2 d}\right]$

$\mathrm{A}$ and $\mathrm{B}$ are constants defined above.

D. B (in meters unit) is varied from 0.005 to -0.005 in the program, as follows, 


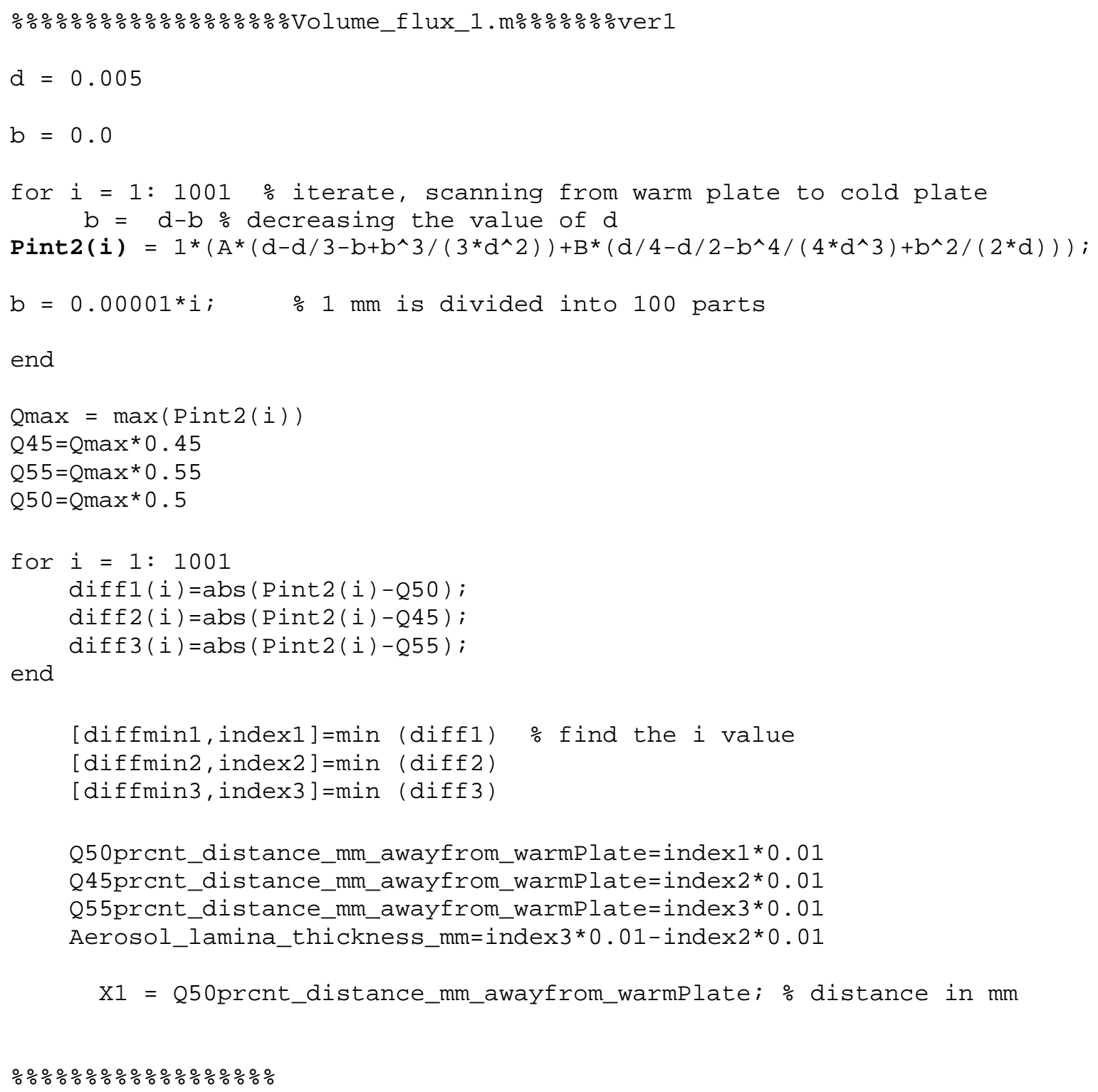

For given input constants $(\Delta T=10$ and total flow $=10 \mathrm{lpm})$, plot of Pint2(i) looks as follows, $\mathrm{x}$ axis has 'i' values and y axis has 'Pint2(i)' values. 


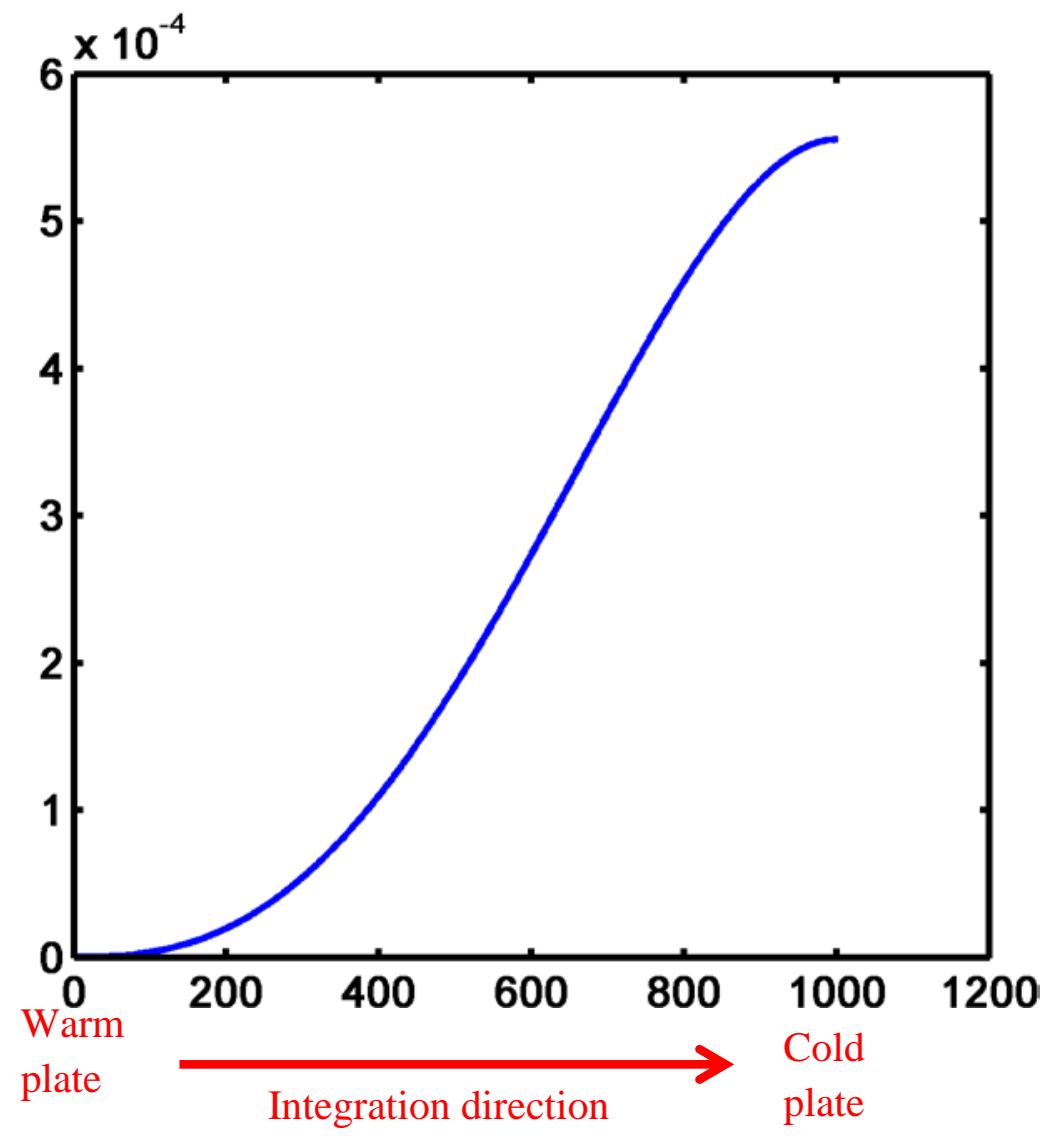

At ' $\mathrm{i}$ ' $=1$, is the warm plate surface and at ' $\mathrm{i}$ ' $=1001$ there is cold plate surface.

At ' $\mathrm{i}$ ' $=1001$, the Pint2(i) magnitude is 5.5556e-04, which is also Q (total mass flux $=2 \mathrm{~d} . \bar{V}$ ).

Therefore, at any 'i' value, also corresponds to the distance between the plates (from warm to cold), the Pint2(i) can be calculated.

For example, $\mathrm{Q} / 2=2.7778 \mathrm{e}-04$ (half of the total flux) is observed at on either side of location ' $\mathrm{i}$ ' $=604$. This ' $i$ ' value translates into $6.04 \mathrm{~mm}$ (see program) away from the warm plate. Also at this distance $(=6.04 \mathrm{~mm})$ the central of the aerosol lamina is located.

The output results are as follows,

$\mathrm{Q} / 2=\mathrm{Q} 50$ prent_distance_mm_awayfrom_warmPlate $=6.0400 \mathrm{~mm}$

Q*0.45 = Q45prcnt_distance_mm_awayfrom_warmPlate $=5.7400 \mathrm{~mm}$

Q*0.55 = Q55prcnt_distance_mm_awayfrom_warmPlate $=6.3300 \mathrm{~mm}$ 
Therefore the aerosol lamina is located between 5.74 and $6.33 \mathrm{~mm}$ distance away from the warm plate. The thickness of aerosol lamina is $0.59 \mathrm{~mm}$. The results depends upon the input conditions, and in this example $\mathrm{Q} * 0.45$ represents $4.5 \mathrm{LPM}$ (one side of the sheath flow) and $\mathrm{Q} * 0.55$ represents the $\mathrm{Q} * 0.45+\mathrm{Q} * 0.1$ which is $5.5 \mathrm{LPM}$ flow (this includes sheath flow and sample flow of $1 \mathrm{LPM}$ ). Using $\mathrm{Q}^{*} 0.55$ we calculate the other coordinate of the aerosol lamina. Plotting the aerosol lamina within the velocity profile looks as follows.

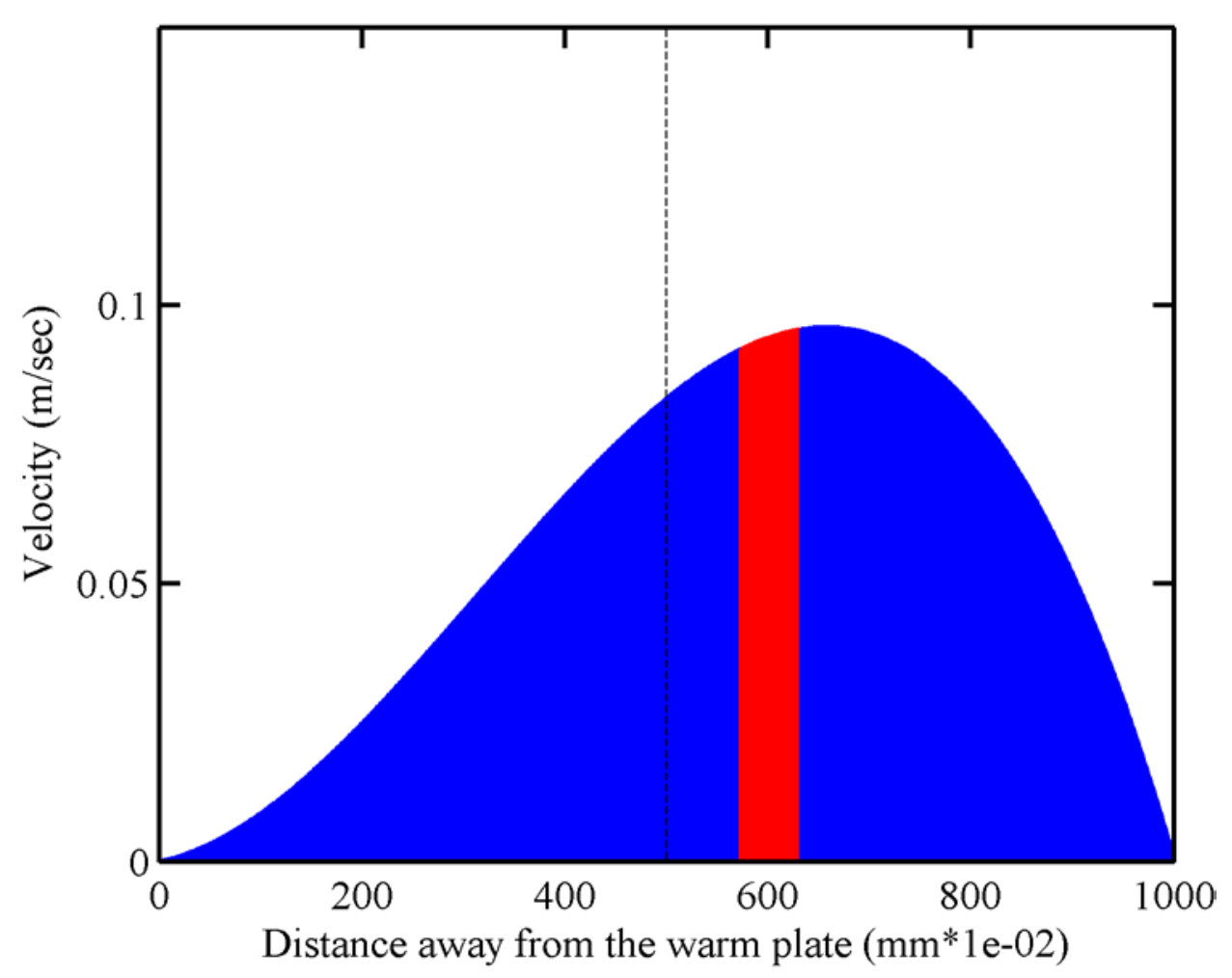

This figure shows the velocity profile between the two plates of the chamber which are maintained at two different temperatures. Warm and cold plates are located on left and right hand, respectively. Red colored shaded area represents the aerosol lamina (carries 10\% of the flow), while the blue color represents the sheath flow regions (carries $90 \%$ of the flow). Vertical dotted line represents the central axis of the chamber. It can be seen that position of maximum velocity is shifted, away from the central axis, towards the cold plate.

\section{CAUTION:}

Under given flow conditions, if the $\Delta T>12$ then the flow reverses near the warm plate leading to miscalculation of the aerosol lamina co-ordinates. 


\section{2) Calculating SS at aerosol lamina coordinates:}

Now the location of aerosol lamina has calculated, as this location is different than the central axis of the chamber, the new coordinates will affect the supersaturation with respect to water $\left(\mathrm{SS}_{\mathrm{w}}\right)$ and ice $\left(\mathrm{SS}_{\mathrm{ice}}\right)$ magnitudes.

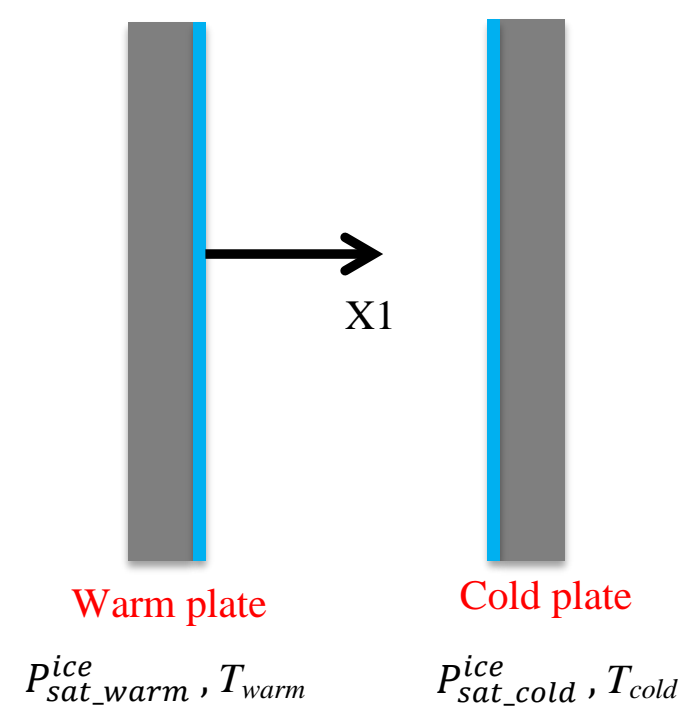

Two vertical plates of ice chamber are maintained at two different temperatures. X1 is the distance from the warm plate where the center of the aerosol lamina is located.

Where $P_{\text {sat_warm }}^{i c e}$ represents saturation vapor pressure over ice at warm plate temperature, $T_{\text {warm, }}$ and similarly $P_{\text {sat_cold }}^{\text {ice }}$ at cold plate temperature, $T_{\text {cold. }}$.

The saturation vapor pressure over ice $\left(P_{\text {sat }}^{i c e}\right)$ and water $\left(P_{\text {sat }}^{\text {water }}\right)$, after Murphy and Koop 2005, at any given temperature, 'Temp_K', is given as below,

$P_{\text {sat }}^{i c e}=\exp \left(9.550426-(5723.265 /\right.$ Temp_K $)+3.53068{ }^{*} \log ($ Temp_K $)-0.00728332 *$ Temp_K $)$;

$P_{\text {sat }}^{\text {water }}=\exp (54.842763-(6763.22 /$ Temp_K $)-$

$4.21 * \log ($ Temp_K $)+\odot .000367 *$ Temp_K $+\tanh \left(\odot .0415^{*}(\right.$ Temp_K -218.8$\left.)\right) *(53.878-$

$\left(1331.22 /\right.$ Temp_K) $-9.44523^{*} \log ($ Temp_K $)+0.014025^{*}$ Temp_K) );

Using these expressions, vapor pressure $(P)$ at any location $(X)$ can be calculated as follows (Rogers 1988),

$$
P=P_{\text {sat_cold }}^{i c e}+\left(\frac{P_{\text {sat_warm }}^{i c e}-P_{\text {sat_cold }}^{i c e}}{2 d}\right) \cdot X 2
$$


Similarly, the temperature $(T)$ at any location $(X)$ can be calculated as follows,

$$
T=T_{\text {cold }}+\left(\frac{T_{\text {warm }}-T_{\text {cold }}}{2 d}\right) \cdot X 2
$$

Where $2 \mathrm{~d}$ is the distance between the plates $(=10 \mathrm{~mm}), \mathrm{X} 2$ is the distance from the cold plate which is,

$$
X 2=2 d-X 1
$$

Thus $S S_{w}(\%)$ at $\mathrm{X} 2$ can be calculated as follows,

$$
S S_{w}(\%)=\left[\left(\frac{P}{P_{\text {sat }}^{\text {water }}(T)}\right)-1\right] \cdot 100
$$

Similarly supersaturation with respect to ice $S S_{i c e}(\%)$ at X2 can be calculated as follows,

$$
S S_{\text {ice }}(\%)=\left[\left(\frac{P}{P_{\text {sat }}^{i c e}(T)}\right)-1\right] \cdot 100
$$

